\title{
Forecasting the Crude Oil Price with Extreme Values
}

\author{
Haibin XIE \\ Research Center of Applied Finance, University of International Business and Economics, Beijing \\ 100029, China \\ E-mail:hbxie@amss.ac.cn
}

Mo ZHOU

University of International Business and Economics, Beijing 100029, China

E-mail: weekendxzr@gmail.com

\section{Yi HU}

School of Management, University of Chinese Academy of Sciences, Beijing 100190, China

E-mail: huyi@amss.ac.cn

Mei YU

University of International Business and Economics, Beijing 100029, China

E-mail:Yumei@uibe.edu.cn

\begin{abstract}
Extreme values are usually given special attention. Using a decomposition-based vector autoregressive (VAR) model, this paper investigates the additional information of extreme values for forecasting the crude oil price. Empirical studies performed on the WTI spot crude oil price over year 1986-2013 are positive: decomposition-based VAR model produces significant both in-sample and out-of-sample forecast. Different evaluation tests are used and the results unanimously report the dominance of decomposition-based VAR over both efficient market model and ARIMA model. These findings are important as they hint that forecasts can be improved if high-low extreme information is properly used. An even more interesting finding is that the predictability of the crude oil price is asymmetric: crude oil price is more predictable in recession than in expansion. This finding is of great significance as it means there is information friction in the oil market especially when the oil price is in recession.
\end{abstract}

Keywords forecast; extreme values; VAR; crude oil price; information friction

\section{Introduction}

Crude oil, known as the blood of industries, plays an important role in the world economies. As one of the main focal point in the world, oil price has become an increasingly essential topic of concern to governments, enterprises and investors. For example, Hamilton noted in a paper published in "Macroeconomic Dynamics" in 2011 that at that time, 10 out of the 11 postwar U.S. recessions had been preceded by a sharp increase in the price of crude petroleum ${ }^{[1]}$. Improving

Received November 17, 2013, accepted February 12, 2014

Supported by National Natural Science Foundation of China (Grant No. 71301160) 
the forecasting accuracy of the oil price is of great interest to both researchers and practitioners. For example, central banks and private sector forecasters take the oil price as one of the key variables in assessing macroeconomic risks. Thus, more accurate forecast of the oil price is of great importance to both policy-makers and investors.

Influenced mainly by the fundamental supply and demand shocks, the crude oil price is also shocked by many other factors such as the environmental disasters, the political events, the speculations, and so on. All these factors contribute to the huge volatility of the oil price and make the oil price forecasting a difficult and challenging job.

In an efficient market, Timmermann and Granger ${ }^{[2]}$ claim that "Stable forecasting patterns are therefore unlikely to persist for long periods of time and will self-destruct when discovered by a large number of investors". Despite the difficulty, voluminous approaches have been devoted to concerning crude oil price forecasting and analyzing. Generally, these approaches can be classified into two categories: structural models and data-driven methods. Structural models attempt to analyze and forecast oil price in terms of supply-demand equilibrium schedule ${ }^{[3-7]}$. In a different way, the data-driven models try to capture the real data generating process (DGP) from the historical price information using either statistical analysis or artificial intelligence. Data-driven approaches include linear models such as Autoregressive Moving Average (ARMA), Autoregressive Conditional Heteroscedasticity $(\mathrm{ARCH})$ type models ${ }^{[8-9]}$ etc., and nonlinear models such as Artificial Neural Network ${ }^{[10-12]}$, pattern matching approach ${ }^{[13]}$, soft computing approach $^{[14]}$, wavelet decomposition and neural network modeling ${ }^{[15]}$. Other references on oil price forecasting and analyzing are included ${ }^{[16-23]}$. Both structure models and data-driven approaches contribute greatly to crude oil price forecasting and analyzing. However, recent advances in behavioral finance highlight new directions for forecasting practice. George and Hwang ${ }^{[24]}$ find that nearness to the 52 -week high dominates and improves upon the forecasting power of past returns (both individual and industry returns) for future returns. Huddart ${ }^{[25]}$ finds that past price extremes (around a stock's 52-week highs and lows) influence investors' trading decisions. $\mathrm{Li}$ and $\mathrm{Yu}^{[26]}$ find that nearness to the 52 -week high positively predicts future aggregate-market returns, while nearness to the historical high negatively predicts future market returns. Baker and Wurgler ${ }^{[27]}$ find that investor sentiment affect stock prices. Joseph et al. ${ }^{[28]}$ find that the investors sentiment help predict abnormal stock returns. Hirshleifer and Teoh ${ }^{[29]}$ and Hirshleifer et al. ${ }^{[30]}$ claim that investors have limited attention.

High-low prices in financial markets are extreme values. Given the limited attention, it can be expected that these extreme values will be given special attention by investors, which in turn will have their impact on investors trading decisions and thus the asset prices. Actually, high-low extreme values have been widely used by investors to read the minds of the market. For example, the Japanese candlestick chart ${ }^{[31]}$ used to and remains to be popular among chartists. Studies have confirmed that high-low extreme values are not only more efficient volatility estimator $^{[32]}$ but also valuable for estimating bid-ask spread ${ }^{[33]}$. Forecasting practice giving no attention to such valuable information would be a great loss and would be less efficient.

In a novel way, Xie and Wang ${ }^{[34]}$ propose to decompose the asset price with high-low extreme values and to predict the asset price with a decomposition-based autoregressive (VAR) model. Since the decomposition-based VAR model employs both closing price and high-low extreme 
values, it naturally offers a nice econometric tool for scrutinizing the value of high-low price information in forecasting practice.

In this paper we start with a brief introduction to the decomposition-based VAR model and finish by applying this technique to forecasting the monthly WTI spot oil price data series. We compare the decomposition-based VAR modeling technique with the efficient market model and with the classic Box-Jenkins ARIMA model. Previewing the results, we obtain the following interesting findings:

First, both in-sample and out-of-sample forecasts demonstrate that the decomposition-based VAR model does report statistically significant and informative forecasts. Different evaluation methods are used to check the robustness of the forecasts, and the results confirm that the crude oil price is predictable. Second, empirical results indicate that the decomposition-based VAR model performs better when the oil price is in recession, which is consistent with the findings of $\mathrm{Li}$ et al. ${ }^{[35]}$ in future oil price and with the information friction theory of Hong et al. ${ }^{[36-37]}$. This finding is important as it indicates that the oil market is not so much efficient as it is commonly believed to be, especially when in recession.

Finally, out-of-sample forecasting results demonstrate the dominance of the decompositionbased VAR model over the ARIMA model, indicating that the high-low extreme price information does contain additional and valuable information for improving the forecasting accuracy. This finding is significant as it hints more historical information is a bless: better forecasts can be achieved if high-low price information is properly used.

The plan for the rest of the paper is as follows. The Section 2 presents the decompositionbased VAR model along with some discussions. Section 3 empirically investigates the performance of the decomposition-based VAR model using the monthly WTI spot oil price data series and compares the results with the efficient market model and with the Box-Jenkins ARIMA model. Section 4 concludes.

\section{Econometric methodology}

In this section, we present a brief introduction to the decomposition-based VAR model and the forecast evaluation criteria.

\subsection{Decomposition-based VAR model}

Traditionally, academic research on financial asset price primary focuses on closing price, giving little or no attention to other price information such as the high-low extreme prices. Recently, Xie and Wang ${ }^{[34]}$ propose to decompose the asset price with high and low prices and to use the decomposition-based VAR model to model asset returns. The idea behind the decomposition of asset returns is straightforward and presented as follows:

$$
\begin{aligned}
\left(H_{t}-L_{t}\right) / C_{t} & =\left(H_{t}-C_{t}\right) / C_{t}+\left(C_{t}-L_{t}\right) / C_{t} \\
& =\ln \left(H_{t} / C_{t}\right)+\ln \left(C_{t} / L_{t}\right)+Q_{t} \\
& =\ln \left(H_{t} / L_{t}\right)+Q_{t},
\end{aligned}
$$

where $Q_{t}=\left[\left(H_{t}-L_{t}\right) / C_{t}\right]-\ln \left(H_{t} / L_{t}\right) . H_{t}, L_{t}$ and $C_{t}$ are respectively the high, low and closing prices. Taking natural logarithmic transformation on both sides of the above equality 
and rearranging gives

$$
\ln \left(C_{t}\right)=\ln \left(H_{t}-L_{t}\right)-\ln \left[\ln \left(H_{t} / L_{t}\right)\right]-\ln \left[1+Q_{t} / \ln \left(H_{t} / L_{t}\right)\right]
$$

where $H_{t}-L_{t}$ and $\ln \left(H_{t} / L_{t}\right)$ are respectively technical range and Parkinson range ${ }^{[32]}$. Technical range is widely used in technical analysis, while Parkinson range is used as a volatility estimator. Denoting $-\ln \left[1+Q_{t} / \ln \left(H_{t} / L_{t}\right)\right]$ as $W_{t}$ and $\ln \left(H_{t}-L_{t}\right)-\ln \left[\ln \left(H_{t} / L_{t}\right)\right]$ as $R_{t}$, we can rewrite Equality (1) as

$$
\ln \left(C_{t}\right)=R_{t}+W_{t}
$$

Equality (2) demonstrates that closing price can be decomposed into a couple of components. Taking differential operation on both sides of (2) yields

$$
r_{t}=\Delta R_{t}+\Delta W_{t}
$$

where $r_{t}=\Delta \ln \left(C_{t}\right)$. Equality (3) is called the technical decomposition of asset returns since only historical price information is employed. A VAR model based on (3) is called a decompositionbased vector autoregressive model. Xie and Wang ${ }^{[34]}$ proves that $\Delta R_{t}$ and $\Delta W_{t}$ are bidirectional Granger-causality. In this paper, the decomposition-based VAR model will be used to investigate the predictability of the crude oil price. A decomposition-based VAR model of $p$ order can be presented as follows:

$$
\begin{aligned}
& \Delta R_{t}=c_{1}+\sum_{i=1}^{p} \alpha_{1, i} \Delta R_{t-i}+\sum_{j=1}^{p} \beta_{1, j} \Delta W_{t-j}+\varepsilon_{1, t} \\
& \Delta W_{t}=c_{2}+\sum_{i=1}^{p} \alpha_{2, i} \Delta R_{t-i}+\sum_{j=1}^{p} \beta_{2, j} \Delta W_{t-j}+\varepsilon_{2, t},
\end{aligned}
$$

where $\varepsilon_{1, t}$ and $\varepsilon_{2, t}$ are unobservable zero mean white noise process (serially uncorrelated or independent).

The vector autoregression (VAR) model ${ }^{[38]}$ is one of the most successful, flexible, and easy to use models for the analysis of multivariate time series. It is a natural extension of the univariate autoregressive model to dynamic multivariate time series. The VAR model has proven to be especially useful for describing the dynamic behavior of economic and financial time series and for forecasting.

\subsection{Forecast construction}

By Equality (3), the forecast of $r_{t}$ can be constructed as follows:

$$
r_{t}^{f}=\Delta R_{t}^{f}+\Delta W_{t}^{f}
$$

where $\Delta R_{t}^{f}$ and $\Delta W_{t}^{f}$ are respectively forecasts of $\Delta R_{t}$ and $\Delta W_{t}$, reported by the decompositionbased VAR model. $r_{t}^{f}$ is the forecast of $r_{t}$.

In this paper, we use the static forecasting procedure to produce the out-of-sample forecast. To be specific, the total sample of $T$ observations for $\Delta R_{t}$ and $\Delta W_{t}$ are divided into two portions: the in-sample portion composed of the first $m$ observations and the out-of-sample portion composed of the last $n(n=T-m)$ observations. When performing out-of-sample forecast, the first $m$ observations are used to estimate the parameters in the decompositionbased VAR model. Keeping fixed these estimated parameters, the out-of-sample forecasts are reported once historical price information is renewed. 
The static forecast is employed to check the robustness of the model structure. As it is well accepted that out-of-sample forecast would be poor if there is any instability in the model structure. Thus, the static forecast offers a nice tool for checking the robustness of model structure.

\subsection{Forecast evaluation}

Commodity market is believed to be efficient and follow a random walk. To see if the decomposition-based VAR model beats the simple random walk model in terms of out-of-sample forecasts, the first forecast evaluation criterion used is the out-of-sample R-square ${ }^{[39]}$ :

$$
R_{\text {oos }}^{2}=1-\frac{\sum_{i=m+1}^{T}\left(r_{i}-r_{i}^{f}\right)^{2}}{\sum_{i=m+1}^{T}\left(r_{i}-\bar{r}_{i}\right)^{2}}
$$

where $r_{t}^{f}$ is the return forecast, $\bar{r}_{t}$ the historical average forecast ${ }^{1}$. If the decomposition-based VAR model reports better forecasts, $R_{\text {oos }}^{2}$ will be positive, which implies a lower mean-squared forecast error (hereafter MSFE) relative to the forecast based on the historical average return. If $R_{\text {oos }}^{2}>0$, the forecast outperforms the historical average return in terms of the MSFE. The null hypothesis of interest is therefore $R_{\text {oos }}^{2}<0$ against the alternative hypothesis that $R_{\text {oos }}^{2}>0$. We test this hypothesis by using the Clark and West ${ }^{[40]}$ MSFE-adjusted statistic. Define

$$
f_{i}=\left(r_{i}-\bar{r}_{i}\right)^{2}-\left[\left(r_{i}-r_{i}^{f}\right)^{2}-\left(\bar{r}_{i}-r_{i}^{f}\right)^{2}\right]
$$

Then, the Clark and West MSFE-adjusted statistic ${ }^{[40]}$ is the t-statistic from the regression of on a constant.

Following [9], we also perform the market timing ability of the decomposition-based VAR model using different ways:

$$
\text { 1. BGJ test: } I\left(r_{i}>0\right)=\alpha_{0}+\alpha_{1} I\left(r_{t}^{f}>0\right)+\xi_{1, i},
$$

where $I(\cdot)$ is the indicator function, which is equal to 1 if its argument is true and 0 otherwise. BGJ test ${ }^{[41]}$ is asymptotically equivalent to a one-tailed test on the significance of the slope coefficient, $\alpha_{1}$.

$$
\text { 2. CM test: } r_{i}=\alpha_{0}+\alpha_{1} I\left(r_{t}^{f}>0\right)+\xi_{2, i},
$$

CM test ${ }^{[42]}$ extended the BGJ test to include not just market timing, but also the magnitude.

$$
\text { 3. BH test: } r_{i}=\alpha_{0}+\alpha_{1} r_{t}^{f}+\xi_{3, i},
$$

$\mathrm{BH}$ test ${ }^{[43]}$ investigates if the forecasts capture any valuable information contained in the real values. In case of statistically significant nonzero of $\alpha_{1}$, the forecasts are said to be informative. In case of $\alpha_{0}=0$ and $\alpha_{1}=1, r_{i}^{f}$ is said to be unbiased forecast of $r_{i}$.

In both the $\mathrm{CM}$ and $\mathrm{BH}$ tests, the null hypothesis is that the slope coefficient is equal to zero, and the alternative hypothesis is a one-sided alternative that the slope coefficient is positive.

In time series forecasting, ARIMA model is the most commonly used econometric tool. To see if high-low price information adds additional information for improving the forecasting

\footnotetext{
${ }^{1}$ The historical average forecast is defined as $\bar{r}_{i}=\frac{1}{i-1} \sum_{t=1}^{i-1} r_{t}$, which simulates the forecast of a random walk (efficient market model).
} 
accuracy, we compare the performance of decomposition-based VAR model with the ARIMA model. To see if the decomposition-based VAR model outperforms the ARIMA model, we report the root-mean-squared-errors (RMSE) and the mean-absolute-errors (MAE) i.e.,

$$
\begin{aligned}
R M S E & =\left[n^{-1} \sum_{i=1}^{n}\left(r_{i}-r_{i}^{f}\right)^{2}\right]^{0.5}, \\
M A E & =n^{-1} \sum_{i=1}^{n}\left|r_{i}-r_{i}^{f}\right| .
\end{aligned}
$$

\section{Empirical results}

This section investigates the empirical performance of the decomposition-based VAR model forecasting and compares the forecasting accuracy between the decomposition-based VAR model and the random walk model, and the ARIMA model.

\subsection{Data}

The monthly spot price data used in this paper is the U.S Cushing, OK WTI Spot Price (Dollars per Barrel). The data sample covers 1986.01-2013.01, with a number of 325 observations $^{2}$. Since the original data set provides no high and low prices, we construct the high and low prices from the closing price as follows:

$$
\begin{aligned}
H_{t} & =\max \left(C_{t}, C_{t-1}, \cdots, C_{t-11}\right), \\
L_{t} & =\min \left(C_{t}, C_{t-1}, \cdots, C_{t-11}\right) .
\end{aligned}
$$

To be specific, the high price is taken to be the maximum price of the 12 consecutive monthly observations, and the low price is take to be the minimum price of the 12 consecutive observations. The high and low prices are constructed in this way for the 52-week (one year) effect: traders use 52 -week high as an anchor ${ }^{[24-26]}$.

From the high and low prices, $\Delta R_{t}$ and $\Delta W_{t}$ can be constructed. Table 1 reports the

Table 1 The summary statistics of $\Delta R_{t}, \Delta W_{t}$ and $r_{t}: 1986.01-2013.01$

\begin{tabular}{lccc}
\hline & $\Delta R_{t}$ & $\Delta W_{t}$ & $r_{t}$ \\
\hline Mean & 0.005526 & 0.000135 & 0.005661 \\
Median & 0.000000 & 0.004279 & 0.012121 \\
Maximum & 0.148181 & 0.297301 & 0.392189 \\
Minimum & -0.174234 & -0.254790 & -0.331981 \\
Std. Dev & 0.037286 & 0.072953 & 0.082176 \\
Skewness & -0.480100 & 0.037146 & -0.248530 \\
Kurtosis & 7.889766 & 4.715737 & 5.592757 \\
Jarque-Bera & $323.8480^{*}$ & $38.46341^{*}$ & $90.89336^{*}$ \\
Obs & 313 & 313 & 313 \\
\hline Note: ${ }^{*}, * * * *$ indicate respectively the significance level of $1 \%, 5 \%, 10 \%$.
\end{tabular}

\footnotetext{
${ }^{2}$ The data set is available at EIA website. http://onto.eia.gov/dnav/pet/hist/LeafHandler.ashx?n= PET\&s $=$ RWTC\& $\mathrm{f}=\mathrm{M}$.
} 
summary statistics of $\Delta R_{t}, \Delta W_{t}$ and $r_{t}$. The summary statistics indicate great price volatility risk of the crude oil market: within one month, the oil price changes can go up as large as $39 \%$ and down as huge as $33 \%$, both of which are 3 times larger than the standard deviation. Consistent with the well documented facts, the oil price changes also exhibit skewness and high kurtosis. Jarque-Bera statistic reveals the abnormal distribution of $\Delta R_{t}, \Delta W_{t}$ and $r_{t}$ at a significance level of $1 \%$.

\subsection{Model estimation}

We perform both in-sample and out-of-sample forecast tests. The in-sample forecast covers the whole data observations. When performing out-of-sample forecast, we divide the whole sample observations into two half parts, the first part (1986.12-2000.12) is used to estimate the parameters in the decomposition-based VAR model. The second part (2001.01-2013.01) is used to perform out-of-sample forecast. The division is typical. For one thing, the cutoff point is almost the middle point of the whole sample; for another, the part used for out-of-sample forecast covers both expansion and recession in the crude oil market.

Lag order selection is of great importance when performing VAR model estimation. As is the usual case that complex models underperform the simple ones when delivering out-of-sample forecast. Therefore, this paper takes the SC (Schwarz Information Criterion) as the order selection criterion. Table 2 reports the order selection criterion performed on the whole sample data. Including the SC, 3 out of 4 criterion prefer VAR(1). Table 3 reports the order selection criterion performed on 1986.12-2000.12. Consistent with the results in Table 2, decomposition-

Table 2 VAR lag order selection criterion (1986.12-2013.01)

\begin{tabular}{cccccc}
\hline Lags & LogL & LR & AIC & SC & HQ \\
\hline 0 & 950.277 & NA & -6.21821 & -6.193814 & -6.208452 \\
1 & 1021.403 & $140.8524^{* *}$ & -6.658379 & $-6.585192^{* *}$ & $-6.629106^{* *}$ \\
2 & 1025.542 & 8.142806 & -6.659292 & -6.537315 & -6.610504 \\
3 & 1030.15 & 9.004745 & -6.66328 & -6.492511 & -6.594976 \\
4 & 1034.533 & 8.507049 & $-6.665790^{*}$ & -6.446231 & -6.577971 \\
\hline
\end{tabular}

Note: ** indicates lag order selected by the criterion. LR: sequential modified LR test statistic (each test at $5 \%$ level); FPE: Final prediction error; AIC: Akaike information criterion; SC: Schwarz information criterion; HQ: Hannan-Quinn information criterion.

Table 3 VAR lag order selection criterion (1986.12-2000.12)

\begin{tabular}{cccccc}
\hline Lags & LogL & LR & AIC & SC & HQ \\
\hline 0 & 522.2859 & NA & -6.503574 & -6.465134 & -6.487965 \\
1 & 568.3548 & $90.41020^{* *}$ & $-7.029435^{* *}$ & $-6.914116^{* *}$ & $-6.982608^{* *}$ \\
2 & 569.9622 & 3.114217 & -6.999527 & -6.807329 & -6.921482 \\
3 & 573.1193 & 6.038059 & -6.988991 & -6.719914 & -6.879728 \\
4 & 578.1088 & 9.417697 & -7.001360 & -6.655403 & -6.860879 \\
\hline
\end{tabular}

Note: ** indicates lag order selected by the criterion. LR: sequential modified LR test statistic (each test at $5 \%$ level); FPE: Final prediction error; AIC: Akaike information criterion; SC: Schwarz information criterion; HQ: Hannan-Quinn information criterion. 
based VAR model of order 1 is also preferred for the sample over 1986.01-2000.12. Table 4 reports the estimation results of $\operatorname{VAR}(1)$ model. To see if there is any great difference when different sample observations are used, we perform decomposition-based VAR estimation on both the whole sample and the subsample over 1986.12-2000.12. Interestingly, we find the results are quite robust: the estimated parameters maintain the same sign and almost the same quantity, which, to some extent, hints the robustness of the decomposition-based VAR model.

Table 4 Results of decomposition-based VAR(1) model estimation

\begin{tabular}{ccccc}
\hline & \multicolumn{2}{c}{$\Delta R_{t}$} & $\Delta W_{t}$ & \multicolumn{2}{c}{$\Delta R_{t}$} & $\Delta W_{t}$ \\
\hline Time & $1986.12-2013.01$ & \multicolumn{1}{c}{$1986.12-2000.12$} \\
$\Delta R_{t-1}$ & 0.489109 & -0.304244 & 0.497474 & -0.299952 \\
t-Statistics & {$[10.2583]$} & {$[-2.90760]$} & {$[7.93192]$} & {$[-2.08927]$} \\
$\Delta W_{t-1}$ & 0.080294 & 0.228585 & 0.113291 & 0.180874 \\
t-Statistics & {$[3.28942]$} & {$[4.26705]$} & {$[3.49566]$} & {$[2.43805]$} \\
Cons. & 0.003204 & 0.001014 & 0.002323 & -0.000795 \\
t-Statistics & {$[1.78270]$} & {$[0.25716]$} & {$[1.04031]$} & {$[-0.15549]$} \\
\hline
\end{tabular}

\subsection{In-sample and out-of-sample forecast}

We perform both in-sample and out-of-sample forecasts. The in-sample forecast covers the whole sample observations over 1986.12-2013.01. In-sample forecast is used to judge how well can decomposition-based VAR model simulates the DGP of the crude oil price. Figure 1 presents the in-sample forecasts of the decomposition-based VAR model. As can be observed that the decomposition-based VAR forecasts fit the observation quite well, especially when the market is in high volatility.

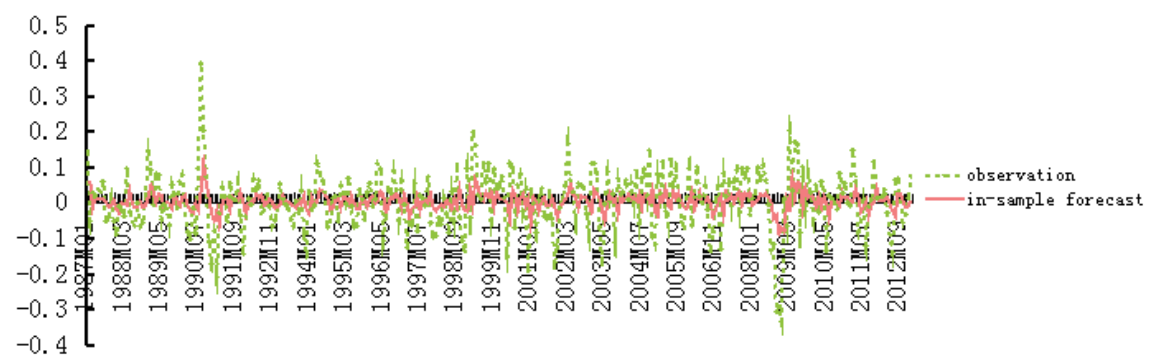

Figure 1 The in-sample forecasts of decomposition-based VAR over 1986.12-2013.01

To quantitatively see how well the decomposition-based VAR model explain the real observations, we perform linear regression test. The result is presented as follows:

$$
r_{t}=-3.10 E-09^{\circ}+1^{* * *} \hat{r}_{t}, R^{2}=8.31 \% .
$$

The result indicates good in-sample forecasts. Regression analysis shows unbiased in-sample forecasts of the decomposition-based VAR model: the slope coefficient is equal to 1 and is statistically significant, while the constant is almost 0 and is insignificantly different from 0 . The R-square indicates that about $8 \%$ variance can be explained away by the decompositionbased VAR model. 
Since out-of-sample forecast carries more weight in practice, we also perform the out-ofsample forecasts over 2001.01-2013.01. To see if the decomposition-based VAR forecast outperforms the simple historical average, we calculate the t-value of the MSFE-adjusted statistic. The t-value is reported to be 2.15 , statistically significant at a level of $5 \%$, which confirms that the decomposition-based VAR model beats the simple historical average. The BGJ, CM, and $\mathrm{BH}$ tests are reported as follows:

$$
\begin{aligned}
\text { BGJ test: } I\left(r_{i}>0\right) & =0.580^{* * *}+0.0937^{\circ} I\left(r_{i}^{f}>0\right), \\
\text { CM test: } r_{i} & =-0.0146^{o}+0.0350^{* *} I\left(r_{i}^{f}>0\right), \\
\text { BH test: } r_{i} & =5.447 E-03^{o}+1.070^{* * *} r_{i}^{f} .
\end{aligned}
$$

The BGJ test result is similar to the findings of [9] who find no direction forecasting ability for monthly returns. Different from [9], the $\mathrm{CM}$ and $\mathrm{BH}$ tests in our empirical studies give positive reports, which consolidates that the decomposition-based VAR model does report significant out-of-sample forecasts. It is interesting to note the BH test: the slope coefficient is about 1 and statistically different from 0 , while the constant coefficient is almost 0 and statistically indifferent from 0 . The $\mathrm{BH}$ test result hints the hypothesis that the out-of-sample forecasts of the decomposition-based VAR model are unbiased. We test the hypothesis using Wald test, and the result indicates the null hypothesis can not be rejected at a significance level of $5 \%$.

\begin{tabular}{|c|c|c|c|}
\hline \multicolumn{4}{|c|}{ Wald Test: $b=1$} \\
\hline Test Statistic & Value & Degree-of-freedom & Probability \\
\hline F-statistic & 0.060515 & $(1,143)$ & 0.8060 \\
\hline Chi-square & 0.060515 & 1 & 0.8057 \\
\hline
\end{tabular}
The Wald test results are reported in Table 5.

Table 5 Wald test results

Goyal and Welch ${ }^{[44-45]}$ provide an useful graphical approach to evaluate the out-of-sample predictive power. This device depicts recursively the residuals to show whether the out-ofsample forecast has a lower MSFE than the historical average forecasts for any period by simply comparing the height of the curve at the beginning and end points of the segment corresponding to the period of interest. If the curve is higher at the end of the segment relative to the beginning, the predictive forecast has a lower MSFE during the period. A predictive forecast that always outperforms the historical average will have a slope that is positive everywhere.

Figure 2 plots the cumulative sum-squared error from the historical average forecasts minus the cumulative sum-squared error from our decomposition-based VAR out-of-sample forecasts. Figure 4 shows some interesting patterns. Positive slope is detected over 2001-2003 and 20082009 when both meet the economic recession: the collapse of the internet bubble and the collapse of the recent subprime bubble. No significant positive slope is observed over 2003-2007 when the economic is in expansion. This pattern indicates that the decomposition-based VAR model outperforms the simple historical average model especially during the economic recession. We test the pattern using the following regression analysis:

$$
r_{i}=7.638 E-03^{o}+0.552^{o} r_{i}^{f} * I\left(r_{i}>0\right)+1.732^{* * *} r_{i}^{f} * I\left(r_{i}<0\right) .
$$


The test result is consistent with Figure 2. When the oil price is in expansion $\left(r_{i}>0\right)$, the slope coefficient is positive but not significant at a level of $10 \%$; while the slope is significant at a level of $1 \%$ when the oil price is in recession $\left(r_{i}<0\right)$. This pattern is consistent with information friction of ${ }^{[36-37]}$ who claim that "bad new travels more slowl", and with the slow information diffusion effect detected by [35] in the oil futures price. Also this pattern has been widely observed in the stock markets, such as [46-48].

Cumulative SSE Difference

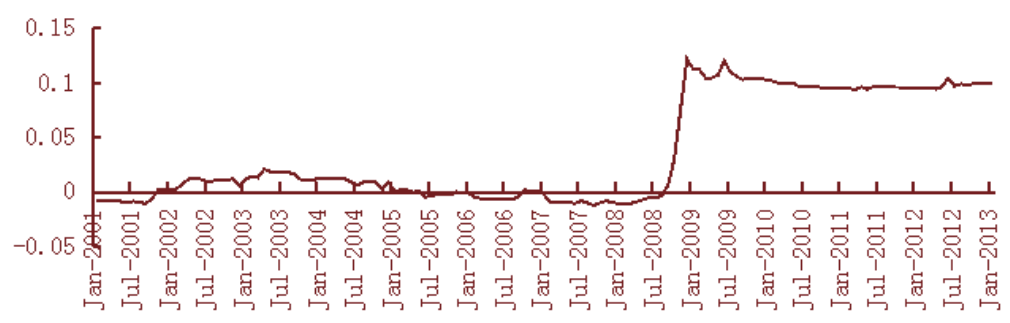

Figure 2 Cumulative relative out-of-sample sum-squared errors (SSE)

\subsection{Out-of-sample forecast: Decomposition-based VAR vs ARIMA}

Another interesting question needs investigating is whether or not the decomposition-based VAR model outperforms the classic $\operatorname{ARIMA}(p, q)$ models. Following the same rule, this paper selects the orders, $p$ and $q$, based on SC. The final ARIMA model used in this paper is presented as follows:

$$
r_{i}=3.06 E-03^{o}+\varepsilon_{t}+0.327^{* * *} \varepsilon_{t-1}-0.277^{* * *} \varepsilon_{t-5} .
$$

To compare the relative performance of decomposition-based VAR and ARIMA, the MAE and RMSE are computed. The results are presented in Table 6. The decomposition-based VAR model outperforms the ARIMA in terms of both MAE and RMSE. To see if the relative gains of the decomposition-based VAR model is statistically significant, we perform Diebold and Mariano (DM) test ${ }^{[49]}$. The t-value for the DM test is 3.36 , statistically significant at a level of $1 \%$, indicating that the decomposition-based VAR model does produce more accurate out-of-sample forecasts.

Table 6 Out-of-sample prediction error comparison:

MAE and RMSE for the sample period from 2001.01-2013.01

\begin{tabular}{ccc}
\hline Out-of-sample forecasts & MAE & RMSE \\
decomposition-based VAR & $6.54 \%$ & $8.30 \%$ \\
ARMA & $7.18 \%$ & $9.08 \%$ \\
\hline
\end{tabular}

Also, we perform the BH test for the ARIMA out-of-sample forecasts:

$$
r_{t}=7.449 E-03^{\circ}+0.285^{\circ} \hat{r}_{t} .
$$

The result indicates the relative poor performance of ARIMA. The slope coefficient is statistically insignificant, indicating the forecasts reported by the ARIMA model is noninformative. Again this result confirms that the high-low extreme values does have additional and valuable information for predicting the crude oil price. 


\section{Conclusions}

As one of the most important energy resources, crude oil price has attracted the attention from all over the world. Improving the accuracy of the crude oil price and understanding the mechanism governing the price evolution is of great interest to researchers and practitioners alike.

With the recent advances in behavioral finance, this paper, using the decomposition-based VAR model, scrutinizes the additional information of high-low extreme values in forecasting crude oil price. The main findings of this paper can be presented as follows:

First, both in-sample and out-of-sample forecasts demonstrate that the decomposition-based VAR model does report statistically significant and informative forecasts.

Second, empirical results indicate that the decomposition-based VAR model performs better when the oil price is in recession.

Finally, out-of-sample forecasting results demonstrate the dominance of the decompositionbased VAR model over both efficient market model and the ARIMA model.

Summarizing these findings, we get the following conclusion:

First, crude oil market is no so much efficient as it is expected to be, there is information friction.

Second, the predictability of crude oil price is asymmetric: crude oil price is more predictable in recession than in expansion. Bad information travels slowly in crude oil market.

Finally and the most importantly, the high-low extreme values have additional and valuable information for improving the forecasting accuracy.

We believe that our efforts make an important step in using high-low price information to predict the crude oil price. We hope that our work will stimulate more interest using high-low price information in forecasting practice.

Acknowledgements We thank the referees for their time and comments.

\section{References}

[1] Hamilton J D. Nonlinearities and the macroeconomic effects of oil prices. Macroeconomic Dynamics, 2011, 15: $364-378$.

[2] Timmermann A, Granger C W J. Efficient market hypothesis and forecasting. International Journal of Forecasting, 2004, 20: 15-27.

[3] Bacon R. Modeling the price of oil. Oxford Review of Economic Policy, 1991, 7: 17-34.

[4] He Y N, Wang S Y, Lai K K. Global economic activity and crude oil prices: A cointegration analysis. Energy Economics, 2010, 32: 868-876.

[5] Huntington H G. Oil price forecasting in the 1980s: What went wrong? The Energy Journal, 1994, 15: $1-22$.

[6] Ye M, Zyren J, Shore J. A monthly crude oil spot price forecasting model using relative inventories. International Journal of Forecasting, 2004, 21: 491-591.

[7] Yang C W, Hwang M J, Huang B N. An analysis of factors affecting price volatility of the US oil market. Energy Economics, 2002, 24: 107-119.

[8] Morana C. A semiparametric approach to short-term oil price forecasting. Energy Economics, 2001, 23: $325-338$.

[9] Sadorsky P. Time-varying risk premiums in petroleum futures prices. Energy Economics, 2002, 24: 539-556.

[10] Mirmirani S, Li H C. A comparison of VAR and neural networks with genetic algorithm in forecasting price of oil. Applications of Artificial Intelligence in Finance and Economics: Advances in Econometrics, 2004, 
19: $203-223$.

[11] Moshiri S. Testing for deterministic chaos in futures crude oil price: Does neural network lead to better forecast? Economics, Working Paper, 2004, 5.

[12] Nelson Y, Stoner S, Gemis G, et al. Results of Delphi VIII survey of oil price forecasts. Energy Report, California Energy Commission, 1994.

[13] Fan Y, Liang Q, Wei Y M. A generalized pattern matching approach for multi-step prediction of crude oil price. Energy Economics, 2008, 30: 889-904.

[14] Ghaffari A, Zare S. A novel algorithm for prediction of crude oil price variation based on soft computing. Energy Economics, 2009, 31: 531-536.

[15] Jammazi R, Aloui C. Crude oil price forecasting: Experiment evidence from wavelet decomposition and neural network modeling. Energy Economics, 2012, 34: 828-841.

[16] Abosedra S, Baghestani H. On the predictability accuracy of crude oil future prices. Energy Policy, 2004, 32: $1389-1393$.

[17] Chaudhuri K. Long-run prices of primary commodities and oil prices. Applied Economics, 2001, 33: 531538.

[18] Huang B N, Yang C W, Hwang C J. The dynamics of a nonlinear relationship between crude oil spot and futures prices: A multivariate threshold regression approach. Energy Economics, 2009, 31: 91-98.

[19] Kang S H, Yoon S M. Modeling and forecasting the volatility of petroleum futures prices. Energy Economics, 2013, 36: 354-362.

[20] Pindyck R S. The long-run evolution of energy prices. The Energy Journal, 1999, 20: 1-25.

[21] Stevens P. The determination of oil prices 1945-1995. Energy Policy, 1995, 23: 861-870.

[22] Yu L, Wang S Y, Lai K K. Forecasting crude oil oil price with an EMD-based neural network ensemble learning paradigm. Energy Economics, 2008, 30: 2623-2635.

[23] Zhang X, Lai K K, Wang S Y. A new approach for crude oil price analysis based on empirical mode decomposition. Energy Economics, 2008, 30: 905-198.

[24] George T, Hwang C. The 52-week high and momentum investing. Journal of Finance, 2004, 59: 2145-2176.

[25] Huddart S, Lang M, Yetman M H. Volume and price patterns around a stock's 52-week highs and lows: Theory and evidence. Management Science, 2009, 55: 16-31.

[26] Li J, Yu J F. Investor attention, psychological anchors, and stock return predictability. Journal of Financial Economics, 2012, 104: 288-302.

[27] Baker M, Wurgler J. Investor sentiment in the stock market. Journal of Economic Perspectives, 2007, 21: 129-152.

[28] Joseph K, Wintoki M B, Zhang Z. Forecasting abnormal stock returns and trading volume using investor sentiment: Evidence from online search. International Journal of Forecasting, 2011, 27: 1116-1127.

[29] Hirshleifer D, Teoh S H. Limited attention, information disclosure, and financial reporting. Journal of Accounting and Economics, 2003, 36: 337-386.

[30] Hirshleifer D, Lim S S, Teoh S H. Limited investor attention and stock market misreactions to accounting information. Review of Asset Pricing Studies, 2011, 1: 35-73.

[31] Nison S. Japanese candlestick charting techniques. New York Institute of Finance, New York, 1991.

[32] Parkinson M. The extreme value method for estimating the variance of the rate of return. Journal of Business, 1980, 53: 61-65.

[33] Cowin S A, Schultz P. A simple way to estimate bid-ask spreads from daily high and low prices. Journal of Finance, 2012, 67: 719-760.

[34] Xie H B, Wang S Y. A new approach to model financial markets. Journal of Systems Science and Complexity, 2013, 26: 432-440.

[35] Li Z R, Sun J J, Wang S Y. An information diffusion-based model of oil futures price. Energy Economics, 2013, 36: 518-525.

[36] Hong H, Lim T, Stein J. Bad new travels slowly: Size, analyst coverage, and the profitability of momentum strategies. Journal of Finance, 2000, 55: 265-295.

[37] Hong H, Torous T, Valkanov R. Do industries lead stock markets? Journal of Financial Economics, 2007, 83: 367-96.

[38] Sims C. Macroeconomics and reality. Econometrica, 1980, 48: 1-48.

[39] Campbell J Y, Thompson S B. Predicting the equity risk premium out of sample: Can anything beat the 
historical average? Review of Financial Studies, 2008, 21: 1509-1531.

[40] Clark T E, West K D. Approximately normal tests for equal predictive accuracy nested models. Journal of Econometrics, 2007, 138: 291-311.

[41] Breen W, Glosten L R, Jagannathan R. Predictable variations on stock index returns. Journal of Finance, 1989, 44: 1177-1189.

[42] Cumby R E, Modest D M. Testing for market timing ability, a framework for forecast evaluation. Journal of Financial Economics, 1987, 19: 169-189.

[43] Bossaerts P, Hillion P. Implementing statistical criteria to select return forecasting models: What do we learn? Review of Financial Studies, 1999, 12: 405-428.

[44] Goyal A, Welch I. Predicting the equity premium with dividend ratios. Management Science, 2003, 49: 639-654.

[45] Goyal A, Welch I. A comprehensive look at the empirical performance of equity premium performance. Review of Financial Studies, 2008, 21: 1455-1508.

[46] Dangl T, Halling M. Predictive regressions with time-varying coefficients. Journal of Financial Economics, 2012, 106: 157-181.

[47] Henkel S J, Martin J S, Nadari F. Time-varying short-horizon predictability. Journal of Financial Economics, 2011, 99: 560-580.

[48] Rapach D E, Strauss J K, Zhou G. Out-of-sample equity premium prediction: Combination forecasts and links to the real economy. Review of Financial Studies, 2010, 23: 821-862.

[49] Diebold F X, Mariano R S. Comparing predictive accuracy. Journal of Business and Economic Statistics, 1995, 13: 253-263. 